Revista Iberoamericana. Vol. LXV, Núms. 188-189, Julio-Diciembre 1999; 505-517

\title{
KALUNGA O EL RECUERDO DE LA TRATA ESCLAVISTA EN ALGUNOS CANTOS AFRO-AMERICANOS
}

\author{
POR \\ MARTín LIENHARD \\ Universität Zürich
}

\section{INTRODUCCIÓN}

Numerosas comunidades latinoamericanas descendientes de africanos conservan o recrean determinados recuerdos de "África" y de la esclavitud. En su narrativa oral, los nagô brasileños y los lukumí cubanos, por ejemplo, evocan las historias de los orishas, antiguos reyes divinizados del país yoruba. Diversas colectividades populares de remota ascendencia cultural bantú, especialmente en Brasil, solían y suelen teatralizar escenas de la vida cortesana de una África mítico-histórica. Como lo demuestran los testimonios de exesclavos que fueron recogidos por diversos antropólogos o historiadores en varios países, la vida bajo el régimen esclavista dejó, también, numerosas huellas en su conciencia. Hay, sin embargo, un momento crucial de la historia de los esclavos que parece haberse borrado de la memoria colectiva de las comunidades de los ex-africanos y sus descendientes en América: el de su "extracción" de África. Si la captura de un africano por los agentes de la trata podía darse en cualquier lugar del continente africano, su transformación definitiva en esclavo se volvía realmente irreversible en el momento en que se lo embarcaba a bordo de un navío negrero. En la vida de los africanos que fueron trasladados a América, la travesía del Atlántico constituía, pues, el momento de transición por excelencia entre su modo de ser y de existir tradicional y su nueva existencia como esclavo. Si las evocaciones historiográficas, novelescas o cinematográficas de la trata suelen dedicar un espacio importante a este momento vivido y "revivido" a lo largo de siglos por millones de africanos, la memoria colectiva de los esclavos y sus descendientes parece haber optado por silenciarlo.

La travesía del Atlántico, que implicaba para las mujeres, los hombres y los niños embarcados la pérdida de su dignidad de seres humanos, fue sin duda alguna, para innumerables generaciones de africanos embarcados hacia América, un momento particularmente traumático. El recuerdo de los traumas, como lo sugieren los estudios modernos de los mecanismos psíquicos individuales, suele quedar relegado, en la memoria humana, a zonas de acceso difícil. Algo análogo parece haberse producido en la memoria colectiva de los africanos y sus descendientes en América. Sin duda, la voluntad colectiva de sobrevivir exige que ciertos episodios particularmente dolorosos de la historia común se cubran con un velo de amnesia colectiva. Si los esclavos americanos optaron por borrar de su memoria activa la travesía del Atlántico, los africanos que permanecieron en África o sus 
descendientes tampoco se mostraron dispuestos o interesados en recordar la deportación de quienes fueron, en un sentido amplio, sus antepasados. Una de las pocas películas africanas que evoca a su manera la historia de la deportación de los africanos para América, Asientos, del cineasta senegalés François Woukouache (Bélgica 1995), sugiere las dificultades inherentes a la empresa de descorrer ese velo hecho de amnesia colectiva. Asientos busca sugerir la historia - propiamente innarrable por la ausencia de fuentes directas- del cautiverio de los africanos destinados a ser embarcados para América. Woukouache optó por mostrar lo poco que podía ofrecer al ojo de su cámara: una antigua factoría portuguesa de esclavos, ubicada en la orilla del mar y transformada en museo, que contenía, fuera de una serie de grabados antiguos, los instrumentos de represión o tortura que se empleaban a lo largo de la trata para domesticar a los cautivos. Sentado en la playa y mirando el mar, un viejo, absolutamente mudo, le "cuenta" a un joven la historia de la deportación. Las imágenes y los elementos sonoros se combinan de manera que el espectador, tomando el lugar del muchacho, logra oír claramente ese relato sin palabras.

Entre los "testimonios" afro-americanos más antiguos se encuentra el siguiente, recogido de boca de un cimarrón colombiano en 1634, en Cartagena, y que demuestra que en la memoria de las colectividades de esclavos, el recuerdo del "camino de África" no se había borrado del todo:

Juan Angola, compañero de este declarante, le dixo que los blancos los traían engañados, y mostrándole el sol le dixo que aquel sol venía de Guinea, ay está el camino, vámonos, y el susodicho y este testigo se fueron por el monte y estubieron en él algún tiempo, que no sabe qué tanto sería, más de que pasó una luna, y luego caminando ffueron a dar a el palenque del Limón (cit. por Kindlimann 43).

Se trata aquí de un texto legal que recoge las declaraciones de Francisco Angola, cimarrón capturado en un ataque al palenque El Limón. Lo que llama la atención en este testimonio es la circunstancia de que para el compañero del declarante, Juan Angola, el camino de "Guinea" ( = África) no parece suponer la travesía — ahora de oeste a este- del Atlántico. Si tomamos al pie de la letra lo que está diciendo, parece que bastaba internarse en la selva y caminar hacia oriente para llegar, tarde o temprano, a África. Al no (querer) recordar la travesía del Atlántico a que fue sometido él mismo o alguno de sus antepasados directos, Juan Angola tampoco puede imaginar cabalmente el camino de regreso a África.

Si en la memoria activa de los esclavos, la travesía del mar no parece, pues, haber dejado huellas, éstas se hallan inscritas en otro tipo de memoria afro-americana: los cantos litúrgicos altamente codificados - a veces crípticos- de ciertas comunidades de descendientes de africanos. Los cantos litúrgicos son el archivo que más se parece, en las culturas afro-americanas, a los archivos escritos del mundo occidental. A raíz de los mecanismos de su trasmisión, que implican entre otras cosas la repetición de enunciados cuyo sentido - o cuya lengua - no se entiende ya del todo, los cantos afro-americanos actuales contienen elementos que hay que atribuir, forzosamente, a "autores" muertos desde hace mucho tiempo. Analizar su letra resulta, pues, una práctica semejante a la que consiste en descifrar - desentrañando los estratos superpuestos- algún manuscrito antiguo. Es en ese tipo de repertorio que buscaremos, a continuación, las posibles huellas del recuerdo 
esclavo de la travesía del Atlántico. Me centraré a continuación en algunos cantos litúrgicos — mambos ${ }^{* 1}$ — del "palo monte", religión afro-cubana cuyos practicantes — "paleros"ubican el lugar de origen de sus antepasados en el área Kongo. ${ }^{2}$

\section{LA TRAVESÍA}

El tema de la deportación marítima se manifiesta, de modo relativamente directo, en algunos cantos paleros. ${ }^{3}$ Las alusiones más claras a la travesía del Atlántico se hallan en los mambos que invocan a la madre de agua o mamita lango (nláng $u^{*}$, en kikongo occidental, significa "agua"):
S Aé, lo madre de n'agua
Aé, mamita lango*
$\mathrm{S} \quad[\ldots]$
S Cabeza kongo* cruzó la má
Cruzó mi nganga*
Cruzó la má
S Ah minganga ndoki*
Cruzó la má
S Mi madre de n'agua
cruzó la má

La travesía del mar -o el viaje marítimo- es el tema de los fragmentos citados. ¿Quiénes fueron los viajeros? Son, sucesivamente, cabeza kongo, nganga, nganga ndoki y mi madre de n'agua. El nombre kongo ${ }^{4}$ remite, por un lado, a los hombres oriundos del área (bantú) Kongo-Angola, especialmente a los llamados “congos reales", ex súbditos del rey del Kongo histórico. En los mambos, sin embargo, este vocablo se aplica en particular al "congo" dotado de los poderes especiales que le otorga su religión: al sacerdote. Por eso

\footnotetext{
${ }^{1}$ Los vocablos seguidos de asterisco se explican en el glosario final.

${ }^{2}$ Mucho más que la santería, el "palo monte", religión marcadamente popular y todavía relativamente secreta, funciona en base a comunidades bastante autónomas y muestra "tendencias" relativamente divergentes en cuanto a sus prácticas rituales : mayombe, kimbisa, brillumba, etcétera. Para los fines específicos y limitados de este trabajo me pareció lícito ignorar tales diferencias. Los mambos cuyos fragmentos se transcriben en este trabajo fueron grabados en la Habana, julio de 1993, en la casa de R. R. S., uno de los tata nganga* del linaje religioso Kalunga Munanzambe. Quiero agradecerle sinceramente a R. , a su padrino y a los compañeros de ambos la amistad, la hospitalidad y la colaboración solícita que me brindaron en esa y en otras oportunidades. Las transcripciones fueron realizadas con la ayuda de $\mathrm{R}$.

${ }^{3}$ Los mambos se cantan según el principio de la antífona: un solista canta el tema, que será luego repetido por la comunidad presente. En el caso de los mambos cubanos, el coro repite siempre el tema inicial, mientras que el solista lo va variando y ampliando. Me limité aquí a transcribir las entradas del solista (S).

${ }^{4}$ En este trabajo, los vocablos Kongo o kongo (con k) se refieren a un territorio africano y a sus habitantes, mientras que con el término "congo" (con c) se remite a las comunidades americanas que se atribuyen -o a quienes se atribuyó- una ascendencia kongo.
} 
mismo, su cabeza, sede de su inteligencia y de su cultura, recibe un énfasis particular. ${ }^{5}$ Ngàngà, en la religión kongo tradicional, es el sacerdote de los nkisi, "divinidades" o "energías" del cosmos natural que se representan bajo forma de estatuas u otros objetos. Entre los paleros cubanos, nganga llegó a ser, también, la propia "divinidad" o el objeto que la representa en el espacio del rito. Ndóki se refiere, en el universo de la religión kongo, al "hechicero". En el "palo monte" o la "regla de congo", la religión de los "paleros" o "congos", ndoki designa más bien al muerto con el cual trabaja el sacerdote o tata nganga. En el mambo citado, nganga ndoki podría remitir sea a los dos tipos de sacerdotes mencionados, sea a nganga con ndoki, expresión que se aplica a la nganga (la "divinidad" presente en su receptáculo) provista de algún elemento del muerto con el cual se desea "trabajar". ${ }^{6}$ La "madre de agua", a su vez, es una nganga o un nkisi que concentra en su "persona" la energía del océano profundo. En la casa habanera donde se grabaron los mambos transcritos, los cantos dirigidos a la "madre de agua" o mamita lango ocupan un lugar preeminente. Esta casa pertenece al linaje religioso Kalunga Munanzambe. En la "lengua" palera, kalunga* es uno de los nombres de la "madre de agua":

S Kalunga sese* [mar blanco o huracanado] ya tá la mesa

S Pá qué me bisa* [llama] mi Madre de agua

S Kalunga sube Kalunga baja

Kalunga también atravesó el mar :

S Kalunga kongo brinca la má

Saca tu mano

tira tu penca

pá curá yo

Cualquiera que fuese la semántica precisa de los nombres africanos que acabo de situar, los mambos citados insisten en que sus portadores atravesaron el mar y llegaron al lugar desde donde están hablando, hoy, los paleros. El kongo, pues, no viajó sólo, sino muy bien acompañado. Para los agentes de la trata y del régimen esclavista, los esclavos no eran seres humanos, sino "piezas": piezas de una maquinaria destinada a producir el máximo con un costo mínimo. Adoptando una perspectiva radicalmente opuesta, el primer mambo enfatiza que quién viajó no fue una "pieza", sino una cabeza: una "inteligencia". Kongo viajó, como diríamos hoy, con todo su bagaje cultural. Los demás pasajeros del viaje fueron, en efecto, agentes o elementos de su universo cultural y religioso. Si la historiografia de la trata suele

\footnotetext{
${ }^{5}$ En las religiones afro-americanas, la cabeza es el objeto de atenciones rituales particulares.

"Como se puede observar, la semántica de estos términos kongo resulta algo fluctuante en la "lengua" de los paleros. Básicamente, esta "lengua" combina rasgos de un lenguaje español pidginizado con un léxico religioso kikongo. A lo largo de la historia de los africanos y sus descendientes en Cuba, muchos términos africanos, sin desprenderse del todo de su semántica de origen, adquirieron, generalmente a partir de un traslado metonímico, un significado nuevo. Si ngàngà designaba en África, como ya se dijo, al sacerdote de los nkisi ("divinidad" o "energía cósmica"), en Cuba, la misma palabra se aplica hoy, preferentemente, a la propia "divinidad" o "energía".
} 
evocar - no sin razón - el desarraigo de los africanos embarcados hacia América, la separación de su cultura de origen que provocaba el traslado de los esclavos a las plantaciones o las ciudades de la otra orilla del Atlántico, el recuerdo de los propios esclavos o de sus descendientes prefiere ver, en la travesía del mar, la expansión de su cultura y religión. La travesía deja así de ser un momento traumático para convertirse en un viaje de afirmación de la fuerza cultural de sus protagonistas.

¿En qué época se habrá fijado ese recuerdo, y quiénes habrán sido sus "autores"? Si los mambos citados pertenecen a la actualidad, su lenguaje hace pensar, sin que podamos en este momento ofrecer elementos probatorios, en la segunda mitad del siglo XIX, época (en Cuba) de grandes movimientos insurreccionales de los esclavos. De cualquier manera, parece verosímil que el "triunfalismo" - por lo menos cultural-que se expresa en estos mambos remite a un momento en el cual la trata ya se daba por concluida y que auspiciaba una toma de conciencia esclava a partir de los elementos africanos "salvados".

KaLUNGA

En la Habana, la Virgen de Regla, patrona del puerto y representación de la orisha marítima Yemayá, es la "santa" más popular, y no sólo entre los practicantes de la santería cubana. El mismo comentario valdría sin duda para la Iemanjá de la ciudad de Salvador da Bahia (Brasil), objeto de un culto masivo. ¿De dónde proviene la popularidad de esta divinidad oceánica? Es altamente probable que se deba, en buena parte, a la historia portuaria de ambas ciudades. Para los adeptos de las religiones afroamericanas de ascendencia yoruba como la santería (Cuba) y el candomblé nagô (Brasil), Yemayá-Iemanjá, en efecto, es el (o la) mar. Hasta el siglo XIX, la historia marítima de La Habana y de Salvador estuvo profundamente ligada a la trata de esclavos. Es en los mambos "congos", sin embargo, donde la relación entre el mar y la trata aparece con máxima nitidez. En su cosmología, el mar aparece como una especie de eslabón que vincula, en la visión de los esclavos o sus descendientes, América a África: un vínculo que resulta al mismo tiempo espacial, histórico y religioso. En términos espaciales, el mar es el elemento que articula y separa simultáneamente los dos continentes vecinos. Históricamente, el mar fue el camino que tuvieron que recorrer los africanos en su deportación hacia América. Desde una perspectiva religiosa, por fin, el mar es el elemento en cuyo fondo viven los espíritus de innúmeros esclavos que murieron en la travesía o que se ahogaron en el naufragio de un barco negrero. En suma, el mar es un espacio central en la historia de la esclavitud y en la cosmología de los esclavos congos o sus descendientes.

En kikongo, uno de los nombres que se emplea para designar al mar es kalunga. Según Wing (83), kalunga es una palabra "muy oscura" que se explica, entre los bampanga (río Inkisi, Congo belga), mediante una adivinanza:

\section{Kalunga nkoko unene, lungila meso, k'ulungila ntambi ko}

Kalunga es un gran río que se puede recorrer con los ojos, pero no con las piernas.

En kikongo, el término más común para referirse al mar (concreto) no es kalunga, sino $m b u^{*}$. Al parecer, kalunga se emplea ante todo en un contexto cosmológico. De hecho, esta 
palabra se considera un préstamo del kimbundu, lengua hablada en la costa central de la actual república de Angola, donde significa "mar profundo", "muerte" y "señor" (Maia). En varias lenguas bantú, kalunga significa, hoy en día, "Dios" (Estermann, II, 211-215). Se puede suponer que ciertos misioneros, a la hora de tener que elegir un nombre para designar en lengua africana a la divinidad suprema de la religión cristiana, dieron su preferencia a kalunga porque este vocablo alude, si no a "Dios", por lo menos a una fuerza particularmente poderosa. António de Oliveira de Cadornega, historiador portugués del siglo XVII, escribió al respecto:

$\mathrm{O}$ nome de Calunga tem duas significações na lingua Ambunda de Angola, porque Calungo [sic] chamão a morte: e chamão Calunga ao mar, que para elles he o mesmo que a morte (Cadornega, I, 414, nota marginal del autor).

La relación de kalunga con la muerte se conoce también en el palo monte. Juan Lara, uno de los informantes de la antropóloga cubana Lydia Cabrera, despliega ampliamente la polisemia de kalunga:

Kalunga [...] significa muchas cosas, porque muerto es Kalunga. Cosa extraña es Kalunga. El cementerio es Kalunga y el infierno y el otro mundo. Y rey es Kalunga. Y mar es Kalunga (Cabrera 177).

Kalunga apunta, pues, a una realidad y a las manifestaciones de una "fuerza" o un "espacio" muy poderoso. A veces se enfatizan unilateralmente sus aspectos más negativos. Es el caso, por ejemplo, de un cuento del escritor - y posterior presidente- angoleño Agostinho Neto, "Náusea", en el cual el viejo João va reflexionando frente al mar:

E o mar é sempre Kalunga. A morte. O mar tinha levado o avô para outros continentes. $O$ trabalho escravo é Kalunga. O inimigo é o mar (21-30).

En la perspectiva histórica adoptada por João e su creador, kalunga resulta, pues, sinónimo de la esclavitud, del colonialismo, de los "blancos". En el film senegalés mencionado al comienzo, Asientos (Woukouache 1995), el mar aparece con las mismas connotaciones negativas. Mirando y acusando el mar, el viejo, sin abrir la boca, le "cuenta" a un joven $-\mathrm{y}$ al espectador- los horrores de la trata de esclavos.

Una observación de Bentley, misionero inglés que trabajaba a fines del siglo XIX en São Salvador (Angola), capital del reino del Kongo, permite confirmar la relación que se estableció, en el imaginario bantú, entre el mar y la esclavitud. El lexicógrafo y gramático inglés afirma, en efecto, que para algunos kongos, el mundo de los espíritus es "a land under the sea, where the departed work for white men, making their cloth and goods" (Bentley 503). Kalunga sería, pues, el paradero de los espíritus de quienes fueron esclavos de los blancos.

En un informe sobre sus negociaciones con el rey de Cabinda o Mamangoy (1784), Andrade, un coronel portugués, afirma que "hera vedado aos Reis de Cabinda o verem mais o mar, Logo que herão elevados ao Trono" (Andrade em Brásio 1-13). Era una norma que 
el rey de Ngoyo, territorio situado al norte del río Zaire, "guardava como seo principal feitiço" (ibid.). Algo sorprendente, este tabú religioso impuesto al jefe de un estado marítimo sugiere que en la cosmovisión de los ngoio, el mar representaba una fuerza temible. Según Fu-Kiau (1969), estudioso de Zaire (actual República Democrática del Kongo), el mar, en la cosmovisión kongo tradicional, era y es un espacio que separa el reino de los vivos del reino de los muertos : un espacio de transición (Thompson 47-55). De acuerdo a la dirección que toma el viaje, la travesía del mar lleva, pues, a la "muerte" o a la "vida". En suma, parece que en las cosmovisiones africanas tradicionales, el mar fue y es un elemento ambivalente, "positivo" y "negativo" al mismo tiempo.

\section{EL PAÍS DE LOS MUERTOS}

En una religión que vive, como la de los "congos" cubanos, de la comunicación entre los practicantes actuales con sus antepasados esclavos y con el espacio originario ("África"), el mar no puede dejar de cumplir una función decisiva. Nótese que en la cosmovisión de los paleros, "África" no se encuentra solamente en la otra orilla, africana, sino también en el mismo fondo del mar. El mar es siempre el mismo mar, el propio mar. Lo expresa a las claras un mambo que pertenece a la misma "serie" que los anteriores:

$\begin{array}{ll}\mathrm{S} & \begin{array}{l}\text { Yo traigo arena } \\ \text { del fondo de la má }\end{array} \\ \mathrm{S} & \text { Yo traigo arena } \\ & \text { pá mi cazuela } \\ \mathrm{S} & \text { Yo traigo arena } \\ & \text { mi madre nganga } \\ & \text { Yo traigo arena } \\ & \text { de tierra ajena }\end{array}$

Cuando necesitan "tierra africana" para completar el contenido de sus cazuelas mágicas, los tata nganga cubanos la extraen "del fondo de la mar". Si el mar es siempre el mismo, vínculo entre América y África, el mar cubano puede perfectamente ofrecer "arena de tierra ajena" (= de África). A raíz del parentesco semántico entre "cementerio" y "mar" (kalunga), resulta verosímil que la arena del mar cumpla, en las prácticas paleras, una función semejante a la de la "tierra de cementerio", otro ingrediente común de las cazuelas mágicas.

¿Cómo se alude a “África” en los ritos paleros? Vimos que una África no directamente nombrada es el punto de partida del viaje marítimo. Acabamos de descubrir, también, que se la alude hablando de "tierra ajena". Hay otro nombre, sin embargo, absolutamente central en el "palo monte", cuya mera enunciación provoca, de alguna manera, la presencia de "África": nfinda*. Este término kikongo, semejante en su polisemia a kalunga, significa "selva" o "monte". Nfinda, como kalunga, es el país de los muertos. En Cuba, uno de los informantes de Lydia Cabrera (123-124) vinculó ambos nombres al declarar que Nfinda Kalunga significaba "cementerio". En el Kongo, como señala Bentley (593), prevalece la idea de que "away in some dark forest land, departed spirits dwell. This spirit land is called 
'nsi a fwa'*, the land of dead, or 'mfinda'*, the forest". En la nfinda de los paleros moran los espíritus de los muertos, de los antepasados. Aunque la nfinda, como el mar, se pueda encontrar en cualquier lugar, la nfinda por excelencia es la de África o, al revés, cualquier bosque tropical - como se vió en el testimonio del cimarrón colombiano- lleva a "África". Ahora, en el país de los muertos situado en el fondo del mar no se encuentran sólo - como en la nfinda - los espíritus de los muertos en general, sino también, y quizás en particular, los de los esclavos que se ahogaron en el mar. En este sentido, la connotación histórica de kalunga resulta mucho más fuerte que la de nfinda. Si el monte o la selva es el espacio primordial anterior al cautiverio esclavista, el mar recuerda el momento (histórico) de la separación, la travesía y la trata en general. En la cosmovisión de los paleros, pues, el mar, vínculo entre África y América, entre el pasado y el presente, entre los orígenes y el momento actual, ocupa, legítimamente, una posición estratégica.

\section{África en los cantos de los Arturos (Brasil): apuntes para un estudio comparativo}

No quiero dejar de hacer constar que en la ritualidad de algunas colectividades populares brasileñas de remota ascendencia bantú se encuentran vestigios de un discurso sobre el "mar" que ofrece varios puntos de convergencia con el de los mambos paleros. Es el caso, por ejemplo, de los Arturos, comunidad negra del estado de Minas Gerais que fue estudiada con gran precisión y sensibilidad por Núbia Pereira de Magalhães Gomes y Edmilson de Almeida Pereira. En el Congado de los Arturos, fiesta del calendario litúrgico católico, el canto de la "guardia de Mozambique" subraya el origen ultramarino de ciertos segmentos de la cultura de los practicantes actuales:
Ah, ei, ingoma*
Ah, ei, ingoma
Essa gunga* vei lá do mar
Correu mundo, correu mar
Correu mundo, correu mar
(Gomes 296)
Aê tambor
Aê tambor
Esa gunga viene del mar
corrió mundo, corrió mar
corrió mundo, corrió mar

La gunga, "latinhas com esferas de chumbo em seu interior e que são amarrados aos tornozelos dos dançantes" (Gomes 529), alude no sólo a un elemento de la cultura bantú que atravesó el mar, sino también a la esclavitud: la gunga era un "sinete usado durante o cativeiro, preso ao tornozelo dos escravos, para denunciar-lhes a fuga" (Gomes). Según los autores del estudio sobre los Arturos, ingoma es un término que se aplica a los danzantes del Congado, pero nombra también "o conjunto da herança recebida dos antepassados" (Gomes). En kikongo, ngòmà designa un tambor muy común. En el canto transcrito, como en los mambos paleros, se enfatiza que los esclavos atravesaron el mar con todo su bagaje cultural. La "guardia del Congo" de los Arturos invoca también una "madre de agua" que 
ofrece varias convergencias con la de los paleros. Ella es, según la tradición oral local (Gomes 299), una Virgen que salvó a los "marineros" (negros) que el dueño de un barco en peligro botó al agua:

\section{$O$ marinheiro \\ Lá no mar balanciô, \\ Ô sereia, ô cai n'agua \\ $\hat{O}$ sereia, $\hat{o}$ lang $\hat{o}^{*}$ \\ Ô pai Xangô ${ }^{*}$}

(Gomes 298)

El nombre principal que se atribuye a la "madre de agua" es sereia ("sirena"). De notoria tradición occidental y de amplia difusión en varias partes de América y de África, sirena es también uno de los nombres que recibe la "madre de agua" de los paleros:

\section{S Sirena sirena}

sirena de la má

Quien fuera marinero

pá ve(r)te navegá

La sirena, como lo muestran los esclarecedores trabajos de Félix Báez-Jorge para América y los de Virgílio Coelho para Angola, suele haber ido incorporando importantes rasgos de divinidades acuáticas locales. Otro nombre que la "guardia del Congo" atribuye a la Virgen salvadora es el de lango (lango-ô). Recordemos que uno de los nombres con que los paleros cubanos invocan a la "madre de agua" es mamita lango, lo que demuestra que Arturos y paleros comparten ciertos recuerdos africanos muy precisos (nlángu*, "agua" en kikongo occidental, es un vocablo muy local en África). Algunos viejos, como señalaron Edmilson y Núbia, recuerdan todavía que la sirena del mar es la antigua "Calunga", ${ }^{7}$ pero esa reminiscencia, dicen, "é tênue, em vias de desaparecimento" (Gomes 389). La invocación final del orisha Xangô (Shangó) delata, obviamente, cierta presencia yoruba en el substrato del texto. Pese a estas evidencias "arqueológicas", la sirena o Virgen no tiene, para los Arturos actuales, ninguna connotación propiamente "africana".

\footnotetext{
${ }^{7}$ La "Calunga" se menciona en muchas otras danzas populares brasileñas, por ejemplo en el Maracatu pernambucano que estudió Mário de Andrade (137-176). En esta danza, "Calunga" designa una muñeca llevada de paseo por la "Dama do Passo". Al explicar la presencia de este nombre africano en la fiesta pernambucana, Andrade, echando mano de toda su erudicción y agudeza, llega a la conclusión siguiente: "calunga (chefe, senhor) veio a significar, por encadeiamento [sic], calunga (boneco atributo político-religioso dos chefes) e, por extensão de sentido, um boneco qualquer" (Andrade 143). Sea correcta o no la interpretación etimológica del investigador y escritor paulista, ella confirma que en este tipo de cultura popular brasileña, kalunga perdió su original semántica bantú para terminar siendo un mero resto arqueológico kongo: una palabra-sonido. (Esta observación no se aplica, obviamente, a las culturas religiosas afro-brasileñas que - como el candomblé de Angolase sirven todavía de una lengua litúrgica de ascendencia bantú.)
} 


\section{CONCLUSIÓN}

Las reflexiones que preceden, apoyadas en los textos de cantos religiosos cubanos y brasileños, demuestran que el momento de la travesía del Atlántico no se borró del todo del recuerdo de los esclavos o sus descendientes, sino que se relegó a zonas relativamente "profundas" de la memoria colectiva. En los cantos brasileños citados, las alusiones a la travesía son reminiscencias dispersas en la arqueología del texto y no vinculadas, por la mayoría de sus depositarios, a la trata esclavista. Concuerda con esta ruptura de la tradición el hecho de que los Arturos, profundamente cristianizados, no reivindiquen explícitamente un pasado remoto africano. Los textos, por lo tanto, parecen "recordar" más que sus depositarios. Sin duda, este comentario se podría aplicar también a los mambos cubanos. Los recuerdos inscritos en los textos sugieren una intensa relación con "África" que no se manifiesta, necesariamente, en la vida cotidiana de sus practicantes. En este caso, sin embargo, la ruptura con "África" es mucho más relativa. La religión palera es de hecho y también en la conciencia de sus practicantes propiamente "afro-cubana" y distinta, pese a ciertas interferencias, de la cristiana. En cuanto al sistema cosmológico que subyace a los mambos, su "africanía", para emplear un término difundido por Fernando Ortiz (1950), es -así por lo menos lo sugieren los cotejos presentados en otro lugar — — bien patente. Para terminar, cabe aclarar que todo este trabajo se refiere a "recuerdos" que constan en la tradición oral comunitaria de los grupos respectivos. Si nos refiriéramos a otro tipo de "recuerdos" colectivos, especialmente a los que provienen de la lectura de estudios sobre la esclavitud o de manifiestos de la militancia negra, el panorama sería bien diferente. Es posible que estos recuerdos "nuevos" terminen también, bajo el impacto de la "reafricanización" de las comunidades de descendientes de africanos, por incorporarse en la tradición oral comunitaria.

\section{GLOSARIO}

Abreviaciones

$\begin{array}{ll}\begin{array}{l}\text { kmb. } \\ \text { pal. }\end{array} & \begin{array}{l}\text { kimbundu } \\ \text { kk. }\end{array} \\ \text { Sw. } & \text { kikongua" de los paleros cubanos } \\ \text { Bisa. } & \text { Swartenbroeckx, Pierre (1973), Dictionnaire kikongo et kituba-français } \\ \text { Gunga. } & \text { Llamar, llama (pal.). Kk. wisa, pedir atención u obediencia (Sw.) } \\ & \begin{array}{l}\text { Enferas de chumbo em seu interior e que são amarrados aos tornozelos dos } \\ \text { dançantes da guarda de Moçambique; sinete usado durante o cativeiro, preso }\end{array} \\ & \begin{array}{l}\text { ao tornozelo dos escravos, para denunciar-lhes a fuga (Gomes 529). Kk. } \\ \text { ngùngà, cencerro, su sonido o llamado, y por extensión, el tiempo de trabajo, }\end{array} \\ & \text { de clase, de estudio (Sw.) } \\ \text { Ingoma. } & \text { Tambor (Arturos, Minas Gerais, Brasil). V. ngoma }\end{array}$

${ }^{8}$ Véase, para mayor información al respecto, mi libro O mar e o mato (1998). 
Kalunga. Mar, océano, país de los muertos (pal.). Kk. kalùnga, océano, mar (Sw.). Bentley afirma que se trata de una palabra oriunda de Angola. Kmb. kalunga, mar profundo, muerte, señor (Maia Dicionário), señora (Cadornega, I,: 414). En varias lenguas bantú actuales, kalunga significa "Dios" (Estermann , II, 211-215).

Lango. Agua - en Mamita lango, madre de agua (pal). Kk. nlángu o m 'lángu, agua, líquido, acuoso (Sw.).

Langô. $\quad$ ¡ Oh agua! (Arturos, Minas Gerais, Brasil). Kk. nláng(u)-ôo, id. (Sw.).

Mambo. Canto ritual (pal.). Kk. màmbì (pl. de diàmbù), negocio, palabra, proceso, relato, conversación ritualizada (Sw.).

Mbú. Mar (kk.).

Mfinda. Véase $n f i n d a$.

Ndoki. Muerto con el cual trabaja el palero (pal.). Kk. ndóki, supuesto autor de un sortilegio nefasto, brujo, hechicero (Sw.). En la cultura kóngo, ndóki es el "hechicero" por excelencia.

Nfinda. Também finda. Monte, bosque, selva, morada de los espíritus de los muertos (pal.). "Aqueles cerrados bosques que este gentio chama enfindas" (Cadornega II/56). Kk. mfinda, id. (Sw.). "El país de los muertos se llama a menudo mfinda" (Bentley 347).

Nfumbi. También fumbi o fumbe. Muerto (pal.). Kk. mvúmbi, cadáver (Sw.).

Nganga (n. m.). También ganga. Término hoy poco usual para nombrar a los tata nganga (v. este término), sacerdotes del palo monte (pal.) En el área Kongo-Angola, sacerdote de la religión de los nkísi (v. este término). "Só consentem que haja gangas, que curem e saquellem [saquem-lhes?] suas enfermidades com paus e hervas, ou com engano ou sem ele" (Cadornega III/262). Kk. ngàngà, mago, adivino, médico ( $\mathrm{Sw}$.)

Nganga (n. f.). También ganga (n. f.), prenda, fundamento. Las "divinidades" o "fuerzas" de la cosmología de los paleros, y los receptáculos donde ellas residen, nkisi (v. este término, muerto (pal.). Si en kikongo, ngàngà se aplica al sacerdote de los nkisi, en la "lengua" palera, nganga pasó, en tanto nombre femenino, a designar las "fuerzas" con las cuales los paleros trabajan.

Nsi a fwa (kk.). País de los muertos (Bentley 593). Kk. nsí, país, región ; mfwà, muerte, muerto (Sw.).

Sese. Palabra oscura que aparece en los mambos paleros. En kikongo, nsêsé significa "blanco", "fulgurante" (Sw.); sese, tempestad, huracán (Laman Dictionnaire). Kalunga sese podría significar, por lo tanto, "mar blanco"o "mar huracanado".

Tata. Padre, sacerdote (pal.). Kk. tâta, padre, pariente paterno, maestro, título de respeto.

Tata nganga. Sacerdote del palo monte (pal.). Kk. tata (v. este término) y ngàngà, hechicero, médico (Sw.).

Xangô. Orisha de origen yoruba, guerrero, vinculado al fuego, a los truenos, etcétera. 


\section{BiBLIOGRAFÍA}

Andrade, Mário de. Danças dramáticas do Brasil. 3 tomos. Belo Horizonte-Brasília: Itatiaia/Instituto Nacional do Livro/Fundação Nacional Pro-Memória, 1982.

Andrade, Pedro Álvares de. "Manuscrito sobre Cabinda". [1784] Angolana (documentação sobre Angola) [I: 1783-1883, II: 1883-1887]. Luanda: Inst. de Investigação Científica de Angola/Lisboa: Centro de Estudos Históricos Ultramarinos, 1968 (I), 1971 (II). 1 13.

Báez-Jorge, Félix. Las voces del agua. El simbolismo de las Sirenas y las mitologías americanas. Xalapa: Universidad Veracruzana, 1992.

Bentley, W. Holman. Dictionnary and Grammar of the Kongo Language, as Spoken at San Salvador, the Ancient Capital of the Old Congo Empire, West Africa. London: Baptist Missionary Society and Trübner, 1887.

Brásio, António. História e missiologia. Inéditos e esparsos. Luanda: Inst. de Investigação Científica de Angola, 1973.

Cabrera, Lydia. El monte. [7ª ed.] Miami: Ediciones Universal, 1992.

Cadornega, António de Oliveira. História geral das guerras angolanas/História geral angolana. [1680]. 3 vols. [I-II: História geral das guerras angolanas; III: História geral angolana]. José Matias Delgado, ed. Lisboa: Agência-Geral do Ultramar, 1972.

Coelho, Virgílio. "Imagens, símbolos e representações. 'Quiandas, Quitutas, Sereias': imaginários locais, identidades regionais e alteridades. Reflexões sobre o quotidiano urbano luandense na publicidade e no universo do marketing". Ngola-Revista de Estudos Sociais I/1 (1997): 127-191.

Estermann, Carlos. Etnografia de Angola (sudoeste e centro). Lisboa: Instituto de Investigação Científica Tropical, 1983.

Fu-Kiau Kia Bunseki-Lumanisa. Le mukongo et le monde qui l'entourait. CosmogonieKôngo. Kinshasa: Office National de la Recherche, 1969.

Gomes, Núbia Pereira de Magalhães e Edmilson de Almeida Pereira. Negras raízes mineiras: os Arturos. Juiz de Fora: Ministério da Cultura/EDUFJF, 1988.

Kindlimann, Adrian. Fluchtgemeinschaften Schwarzer Sklaven in Cartagena de Indias (1540-1714). Inédito. Zürich: Universität Zürich, 1994.

Laman, Karl. Dictionnaire Kikongo-français, avec une étude phonétique décrivant les dialectes les plus importants de la langue dite kikongo. Bruxelles: Institut Royal Colonial Belge, Section des Sciences Morales et Politiques, 1936.

Lienhard, Martin. Omare o mato-histórias da escravidão(Congo-Angola, Brasil, Caribe). Salvador da Bahia: Centro de Estudos Afro-Orientais, Universidade Federal da Bahia, no prelo, 1998.

Maia, António da Silva. Dicionário complementar português-kimbundu-kikongo. [1964]. Lisboa: Cooperação Portuguesa, 1994.

Neto, Agostinho. Náusea. Lisboa: Ed. 70, 1980.

Oliveira, Mário A. Fernandes de. Angolana (documentação sobre Angola). I: 1783-1883, II: 1883-1887. Luanda: Inst. de Investigação Científica de Angola/Lisboa: Centro de Estudos Históricos Ultramarinos, 1968 (I), 1971 (II). 
Ortiz, Fernando. La africanía de la música folklórica de Cuba. La Habana: Ministerio de Educación, Dirección de Cultura, 1950. Reed. La Habana: Editora Universitaria, 1965.

Swartenbroeckx, Pierre. Dictionnaire kikongo et kituba-français. Bandundu (Zaire): CEEBA, 1973.

Thompson, Robert Farris. Face of the gods. Art and altars of Africa and the African Americas. New York: The Museum for African Art, 1993.

Wing, R. P. van. Etudes bakongo: histoire et sociologie. Bruxelles: Goemaere, 1921. 
